\title{
Smoking cessation education and training in UK nursing schools: A national survey
}

\author{
Becky Richards ${ }^{1,2}$, Ann McNeill ${ }^{3}$, Emma Croghan ${ }^{4}$, J ennifer Percival ${ }^{5}$, Deborah Ritchie ${ }^{6}$, Andy \\ McEwen ${ }^{1}$
}

1. Department of Epidemiology \& Public Health, University College London, London, UK. 2. Cochrane Institute of Primary Care and Public Health, Cardiff University, Cardiff, UK. 3. Institute of Psychiatry King's College London, London, UK. 4. Public Health and Lifestyle Services, Nottingham, UK. 5. Royal College of Nursing, England, UK. 6. School of Health in Social Science, University of Edinburgh, Edinburgh, UK.

Correspondence: Becky Richards. Address: Department of Primary Care \& Public Health, Cardiff University School of Medicine, Wales, UK. Email: richardsb3@cardiff.ac.uk

Received: April 10, 2014

DOI : $10.5430 /$ jnep.v4n8p188
Accepted: June 9, $2014 \quad$ Online Published: June 25, 2014

URL: http://dx.doi.org/10.5430/jnep.v4n8p188

\section{Abstract}

Smoking remains the leading cause of preventable, premature death in the UK. Very Brief Advice (VBA) from Health Care Professionals (HCP) can trigger quit attempts, and behavioural support from trained practitioners can assist with these quit attempts. The purpose of the current study was to assess the self-reported content of smoking cessation education, and extent of training, in pre-registration nursing schools in the UK. Seventy-one UK nursing schools were invited to complete a web-based survey that measured smoking cessation content and training on nursing curricula. Thirty-two (45\%) nursing schools responded to the survey. Almost all schools (91\%) reported including the harmful effects of tobacco use on their curriculum, however only around half of schools reported teaching nicotine addiction and its treatment. Just under two-thirds of schools (66\%) reported providing training to deliver brief interventions to smokers. Over a third of schools (38\%) reported spending under three hours teaching smoking cessation throughout the entire programme. Only $6 \%$ of schools reported examining students on what they had been taught. Lack of knowledge amongst staff and uncertainty about who should deliver the teaching was reported as barriers to teaching. Gaps in UK nursing curricula, including training in smoking cessation interventions and in examining what has been taught, are likely contributing to the less than optimum smoking cessation interventions delivered by UK nurses in practice.

\section{Key words}

Nursing schools, Smoking cessation, Education, Training

\section{I ntroduction}

Smoking remains the leading cause of preventable, premature death in the UK ${ }^{[1]}$. Despite reduced prevalence of smoking in the UK over recent decades, there are still over 9.5 million adult smokers ${ }^{[2]}$. The English Government launched its Tobacco Control Plan in March 2011, with the aim of reducing adult smoking prevalence to $18.5 \%$ or less by $2015^{\text {[3] }}$; and other nations within the UK have also published plans for the reduction of smoking prevalence ${ }^{[4,5]}$. Quitting smoking at all ages substantially reduces the risk of smoking-related excess morbidity and mortality ${ }^{[6]}$ and there is good evidence for the 
effectiveness of behavioural and pharmacological smoking cessation interventions ${ }^{[7]}$. Advising and assisting more smokers to quit is imperative in order to reduce the burden of smoking in the $\mathrm{UK}^{[8]}$.

One way of classifying smoking cessation interventions is to make a distinction between interventions that trigger quit attempts and interventions that assist quit attempts. Interventions that trigger quit attempts include Very Brief Advice (VBA) on smoking from a Health Care Professional (HCP). Interventions that aid quit attempts include behavioural support, nicotine replacement therapy (NRT) and other pharmacotherapy (e.g. varenicline) ${ }^{[9]}$. VBA involves establishing a patient's smoking status (Ask), advising the patient that the best way to quit is through a combination of evidence-based support and medication (Advise) and referring those who wish to quit to a stop smoking service (Act), where they are then four times more likely to quit than if they had attempted to quit unaided ${ }^{[10]}$. Brief advice on smoking has been shown to be the most cost-effective HCP intervention currently available ${ }^{[11]}$. A recent review of thirteen studies showed that opportunistic brief advice from a physician significantly increased the number of smokers' quit attempts by $24 \%$ compared to no intervention, however offering assistance was found to double quit attempts compared to advice alone ${ }^{[12]}$. Authors concluded that advising smokers to quit combined with the offer of assistance has the greatest likelihood of increasing smoking cessation rates. Training frontline NHS staff to deliver 30-second VBA on smoking as part of routine practice is consistent with the Department of Health's 'Make Every Contact Count' (MECC) ${ }^{[8]}$.

It has been argued that brief advice and assistance from nurses would be more cost-effective than from a physician ${ }^{\text {[13] }}$. Nurses are the largest group of HCP and have access to a large number and wide range of smokers ${ }^{[14]}$. Nurses are therefore well placed to intervene with smokers, as recommended by smoking cessation guidelines for health professionals ${ }^{[9]}$. The efficacy of a nurse's role in smoking cessation is supported by a review of smoking cessation interventions (including advice to quit smoking, counselling and/or strategies to help patients quit) provided by nurses across a variety of settings ${ }^{[15]}$. Results showed that smokers who participated in nurse-managed interventions were $28 \%$ more likely to be abstinent at 6 months or longer compared to no intervention or usual care; however low intensity interventions, such as advice to stop smoking (lasting up to 10 minutes with one follow-up visit), revealed both small and non-significant effects. It must be noted that no studies solely examined provision of VBA by a nurse. Despite these small effects, low intensity interventions such as VBA may translate into a large public health benefit given the wide reach of nurses ${ }^{[16]}$.

In order to deliver successful interventions, nurses must be knowledgeable and adequately trained ${ }^{[7]}$. Studies suggest that it would be cost-effective to train nurses in smoking cessation as training programmes have been shown to increase both the amount of VBA and assistance offered by nurses ${ }^{[17]}$. A recent pilot study in the UK demonstrated the potential of training nurses for no longer than 15 minutes in VBA ${ }^{[16]}$. Hospital staff was trained to deliver 30-second VBA to inpatient smokers and use an electronic referral system linked to local stop smoking services. Results showed a $602 \%$ increase of referrals to stop smoking services compared to before the implementation of training and the referral system. Training pre-registration nurses in VBA would appear prudent as there is now an expectation that all nurses, regardless of role, should deliver opportunistic brief advice to all of their patients who smoke ${ }^{[8]}$.

Despite enthusiasm from nurses to help smokers quit ${ }^{[18]}$, studies have found a lack of education (knowledge) and training (practice) in interventions among nurses that impact upon clinical practice ${ }^{[18-21]}$. In the UK, a survey of 459 practice nurses in England and Wales found that $40 \%$ of nurses had not been trained in smoking cessation; subsequently only $42 \%$ of nurses thought the cost of NRT was justified and 21\% of nurses were either uncertain or did not believe that NRT increases a smoker's chance of quitting ${ }^{[22]}$. Nurses that had not been trained were less likely to report providing advice, assistance, or recommend NRT to smokers wanting to quit.

The World Health Organisation has recommended the inclusion of tobacco control on all curricula for health professionals ${ }^{[23]}$. Despite this, a recent study of undergraduate medical programmes in the UK suggests that lack of smoking cessation education and training among HCP may be due to a lack of education and training on curricula ${ }^{[24]}$. The majority of medical graduates have received little or no training in the practical delivery of smoking cessation interventions. The 
study also found that only $10 \%$ of graduates felt prepared to deliver practical guidance on smoking cessation, less than $20 \%$ felt prepared to discuss NRT and only 5\% felt prepared to discuss the smoking cessation medication buproprion. Lack of space on the curriculum, lack of adequately trained staff and uncertainty about who should deliver teaching were cited as barriers to teaching smoking cessation. Furthermore, although the UK Nursing and Midwifery Council (NMC) curriculum guidelines state a commitment to identification and utilisation of health promotion opportunities, there are no current guidelines on the teaching of promotion and assistance of smoking cessation ${ }^{[25]}$.

Studies of international nursing curricula have highlighted that this problem is not confined to the UK, particularly in relation to teaching of nicotine addiction and its treatment, and training in VBA and practical skills to deliver intervenetions ${ }^{[26-28]}$. The majority of international nursing programmes fail to include topics that are fundamental to the delivery of smoking cessation interventions, such as nicotine withdrawal symptoms ${ }^{[28-30]}$, NRT, other pharmacotherapy and delivery of VBA ${ }^{[28,30]}$. The limited number of hours reportedly allocated to smoking cessation teaching on international nursing curricula may also reflect the low priority of this topic ${ }^{[7]}$.

There are currently no studies of smoking cessation education on nursing curricula in the UK. It is important to assess the current state of smoking cessation teaching and training on UK nursing curricula in order to identify whether nursing programmes are adequately preparing nurses to meet government initiatives ${ }^{[3,8]}$. The present study aimed to answer the following research questions:

1) What specific programme content is included and are students examined on the acquisition of knowledge and skills?

2) Are students provided with training on how to deliver brief interventions (e.g. VBA) to smokers?

3) Does the curriculum include teaching on ways to assist smokers to make a quit attempt? (e.g. use of smoking cessation medications and behavioural support)

4) How many hours of teaching are allocated to smoking cessation, who is this taught by and in what year(s) does it take place?

5) What barriers do respondents think are in place to the teaching of smoking cessation?

\section{Method}

\subsection{Design}

Cross-sectional, web-based survey administered between June and July, 2013.

\subsection{Participants}

Universities with an accredited, undergraduate nursing programme in England ( $n=54)$, Northern Ireland $(n=2)$, Scotland $(n=10)$ and Wales $(n=5)$ were invited to participate in the study. A list of accredited, undergraduate nursing programmes was sourced from The Nursing and Midwifery Council website. A suitable faculty member for each programme, such as head of the nursing department, was sourced from individual university websites. An email consisting of a cover letter explaining the study was sent to each contact to establish the most appropriate recipient of the survey; they were each requested to forward the email to the most appropriate faculty member, if not them. For participants that were not contactable during the survey period, an alternative contact was sourced through individual university websites in order to maximise chances of the survey being completed by all universities. A final list of participants was identified through no reply and returned emails $(n=71)$. 


\subsection{Survey development}

A review of the literature was undertaken to inform the development of an initial survey. The current survey was adapted from a UK survey of smoking cessation teaching in medical schools ${ }^{[24]}$. Two nurses with expertise in smoking and smoking cessation reviewed the survey for content validity, understanding and ease of completion, prior to pilot testing. Only minor modifications were suggested for clarification. This amended online survey was piloted by staff of the National Centre for Smoking Cessation and Training (NSCST) and a review of technical issues was undertaken. The final survey was uploaded online and a Microsoft Word version of the survey was also created, which matched the web-based survey in presentation to ensure equivalence ${ }^{[31]}$ (see supplementary files).

\section{Procedure}

Each participant was sent an email pre-notification of intent to survey that included a personalised cover letter explaining the study and a request of participation on behalf of their institution. A second email containing a hyperlink to the web-based survey was sent four weeks later to all participants. For non-responders, two personalised reminder emails, that included the Word version of the survey as an email attachment, were sent 7 and 14 days after the survey went live in order to increase response rates ${ }^{[32,33]}$. The study was approved for exemption status by UCL Graduate School Ethics Committee as it was deemed to be an evaluation conducted solely to define and assess current nursing curricula in the UK. Consent was implied by participants completing and submitting the survey.

\subsection{Survey}

The survey consisted of 28 items that requested information on the demographics, position and department of the respondent, teaching of harmful effects of tobacco use, contents of teaching, training to deliver brief interventions (e.g. VBA) and teaching of ways to assist quit attempts. The contents of teaching included checkboxes for: contents of tobacco smoke; health risks of smoking and benefits of quitting; pharmacology of nicotine addiction; nicotine withdrawal symptoms; NRT and other pharmacological agents; the role of the stop smoking services; determinants and demographics of smoking; smoking in pregnancy; smoking and mental health; population strategies; cost- and clinical-effectiveness of interventions; harm reduction; and practical delivery in artificial and clinical settings. The survey also requested information on the number of teaching hours allocated to smoking cessation, the placement of teaching on the programme by year, the individual/organisation responsible for the delivery of teaching and the inclusion of an examination on what had been taught. The survey also identified possible barriers to teaching. Finally, respondents were asked to rate students' ability to deliver interventions upon completion of the programme.

\subsection{Data analysis}

Data were cleaned, duplicate data was removed and missing data was coded for analysis. The final data set was transferred to SPSS for Windows (Version 21) for analysis. Descriptive statistics were used to summarise data and chi-square analyses were used to determine the associations between independent variables: 1) country, 2) teaching hours, 3) year(s) of teaching, 4) attitudes to barriers of teaching; and the dependent variables: 1) teaching of harmful effects of tobacco use, 2) training to deliver brief interventions, 3) teaching of ways to assist quit attempts, 4) inclusion of examinations, and 5) respondents' ratings of students' ability to deliver interventions. As these variables had more than $25 \%$ of cells with counts less than 5, two-tailed Pearson Chi-Square Exact tests were used to compare variables with more than two levels and two-tailed Fisher's Exact tests were used to compare variables with two levels. Alpha was set to .05 for all statistical tests.

Due to the large number of tests run, only significant associations are presented. Full analysis is presented in supplementary files, where appropriate. Missing values were removed from analysis to provide valid percentages. For the purpose of analysis, teaching hours were collapsed into two groups; 'less than 3 hours' (' $<1$ hour' and ' $1-3$ hours') and 'more than 3 hours' ('3-5 hours' and ' $>5$ hours'), and 'don't know' responses were removed from analysis. Attitudes to barriers of teaching were collapsed into three groups; 'agree' ('strongly agree’ and 'agree'), 'disagree' ('strongly disagree' and 'disagree') and 'neither agree nor disagree'. Respondents' ratings of students' ability to deliver interventions were 
collapsed into three groups; 'excellent/good' ('excellent' and 'good'), 'poor' and 'fair', and 'not applicable' responses were removed from analysis. 'Don't know' responses for the following items were removed from subsequent analysis: teaching of harmful effects of tobacco use, training to deliver brief interventions, teaching ways to assist quit attempts and placement of teaching by year. For descriptive purposes, tables and figures are presented with collapsed number of groups.

\section{Results}

After an initial response from 14 universities (20\%), a first reminder yielded a further 11 responses (15\%) and a final reminder yielded a further 10 responses (14\%). Three duplicated responses were removed from analysis, resulting in an effective response rate of $45 \%(n=32)$. Data were obtained from 22 nursing schools in England (41\% of 54), two in Northern Ireland (100\%), five in Scotland (50\% of 10) and three in Wales (60\% of 5). Twenty-one responses (66\%) came from faculty of nursing departments and eleven responses (34\%) from faculty of health science departments. Nearly two-thirds $(62.5 \%, n=20)$ of those completing the survey on behalf of their institution were female. Most respondents were senior lecturers (38.7\%) or programme directors (25.8\%) of nursing and one respondent reported 'other' but failed to specify further (see Table 1).

Table 1. Positions of respondents $(n=31)$

\begin{tabular}{ll}
\hline Position & Percentage (n) \\
\hline Principal & $3.2 \%(\mathrm{n}=1)$ \\
Head of department & $9.7 \%(\mathrm{n}=3)$ \\
Programme director & $25.8 \%(\mathrm{n}=8)$ \\
Lecturer & $19.4 \%(\mathrm{n}=6)$ \\
Senior lecturer & $38.7 \%(\mathrm{n}=12)$ \\
Other & $3.2 \%(\mathrm{n}=1)$ \\
\hline
\end{tabular}

Almost all schools (90.6\%) reported teaching the harmful effects of tobacco use and more than three quarters reported teaching ways to assist quit attempts, however under two-thirds of schools reported training students in how to deliver brief interventions (see Table 2).

Individual smoking and smoking cessation topics reported to be included on curricula are presented in Table 3 . The vast majority of schools reported including the health effects of smoking such as cancer risks, cardiovascular health effects, passive smoking and smoking in pregnancy; whilst the pharmacology of nicotine addiction was covered by the least number of schools. Only just over half of schools reported teaching nicotine withdrawal symptoms and a similar proportion reported teaching about NRT. Only half of schools reported teaching about other pharmacological agents (e.g. varenicline) and just over half reported teaching about the cost- and clinical-effectiveness of smoking cessation interventions. Under one-third of schools reported teaching practical delivery in artificial settings and one-third reported teaching practical delivery in clinical settings.

Table 2. Inclusion of smoking cessation teaching and training on UK nursing curricula

\begin{tabular}{|c|c|c|c|c|}
\hline & \multicolumn{3}{|l|}{ Percentage (n) } & \multirow{2}{*}{ Total } \\
\hline & Yes & No & Don't know & \\
\hline Teaching of harmful effects of tobacco use & $90.6 \%(n=29)$ & $6.3 \%(n=2)$ & $3.1 \%(n=1)$ & $\mathrm{n}=32$ \\
\hline Training in how to deliver brief interventions (e.g. the 4 A's) & $65.6 \%(n=21)$ & $31.3 \%(n=10)$ & $3.1 \%(n=1)$ & $\mathrm{n}=32$ \\
\hline $\begin{array}{l}\text { Teaching of ways to assist quit attempts (e.g. smoking } \\
\text { cessation medications and behavioural support) }\end{array}$ & $78.1 \%(n=25)$ & $18.8 \%(n=6)$ & $3.1 \%(\mathrm{n}=1)$ & $\mathrm{n}=32$ \\
\hline
\end{tabular}


Table 3. Individual smoking and smoking cessation topics included on UK nursing curricula $(n=30)$

\begin{tabular}{|c|c|}
\hline Content area & Percentage (n) \\
\hline \multicolumn{2}{|l|}{ Smoking topics } \\
\hline Contents of tobacco smoke & $63.3 \%(n=19)$ \\
\hline Cancer risks & $86.7 \%(n=26)$ \\
\hline Cardiovascular health effects & $93.3 \%(n=28)$ \\
\hline Passive smoking & $80 \%(n=24)$ \\
\hline Pharmacology of nicotine addiction & $43.3 \%(n=13)$ \\
\hline Determinants of smoking & $63.3 \%(n=19)$ \\
\hline Demographics of smoking & $70 \%(n=21)$ \\
\hline Smoking in pregnancy & $80 \%(n=24)$ \\
\hline Smoking and mental health & $63.3 \%(n=19)$ \\
\hline \multicolumn{2}{|l|}{ Smoking cessation topics } \\
\hline Benefits of cessation prior to surgery & $70 \%(n=21)$ \\
\hline Nicotine withdrawal symptoms & $53.3 \%(n=16)$ \\
\hline Population strategies & $63.3 \%(n=19)$ \\
\hline Cost- and clinical-effectiveness of smoking cessation interventions & $53.3 \%(n=16)$ \\
\hline Harm reduction & $70 \%(n=21)$ \\
\hline Nicotine replacement therapy (NRT) & $56.7 \%(n=17)$ \\
\hline Other pharmacological agents & $50 \%(n=15)$ \\
\hline The role of the stop smoking services & $76.7 \%(n=23)$ \\
\hline Practical delivery in artificial settings (e.g. role play) & $30 \%(n=9)$ \\
\hline Practical delivery in clinical settings (e.g. observing a stop smoking practitioner) & $33.3 \%(n=10)$ \\
\hline
\end{tabular}

Over one-third of nursing schools reported spending under three hours teaching smoking cessation throughout the entire programme (see Table 4). The majority of schools reported that smoking cessation teaching occurred during the first two years of the programme, however responses to this item were not mutually exclusive (see Table 5). Over three-quarters of schools $(77.4 \%, n=24)$ reported that a member of staff delivered the teaching, 9.7\% $(n=3)$ an external lecturer, one respondent (3.2\%) reported 'other' but failed to specify who and 9.7\% $(\mathrm{n}=3)$ did not know. Only two schools $(6.4 \%)$ reported examining students on what had been taught upon completion of the programme.

Table 4. Reported hours of smoking cessation teaching $(n=32)$

\begin{tabular}{ll}
\hline Number of hours & Percent $(\boldsymbol{n})$ \\
\hline$<1$ hour & $6.3 \%(n=2)$ \\
$1-3$ hours & $31.3 \%(n=10)$ \\
$3-5$ hours & $25 \%(n=8)$ \\
$>5$ hours & $18.8 \%(n=6)$ \\
Don't know & $18.8 \%(n=6)$ \\
\hline
\end{tabular}

Table 5. Reported frequency of teaching by year $(n=32)$

\begin{tabular}{ll}
\hline Teaching by year & $\boldsymbol{n}$ \\
\hline Year 1 & 18 \\
Year 2 & 21 \\
Year 3 & 10 \\
Year 4 & 1 \\
Don't know & 2 \\
\hline
\end{tabular}


Students' ability to deliver interventions were rated excellent or good by over a half of respondents for very brief advice to stop smoking (see Figure 1), 40\% ( $n=12)$ for behavioural support (see Figure 2) and just over one quarter for advice on smoking cessation medications (see Figure 3).

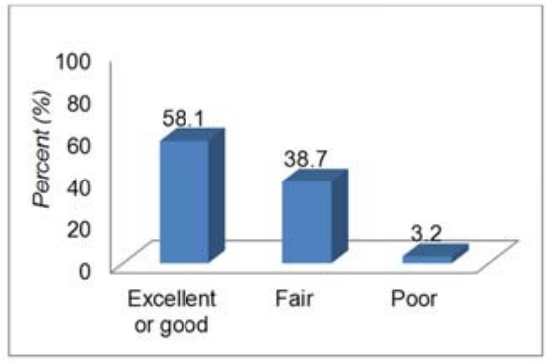

Figure 1. Respondents' ratings of students' ability to deliver very brief advice to stop smoking $(\mathrm{n}=31)$

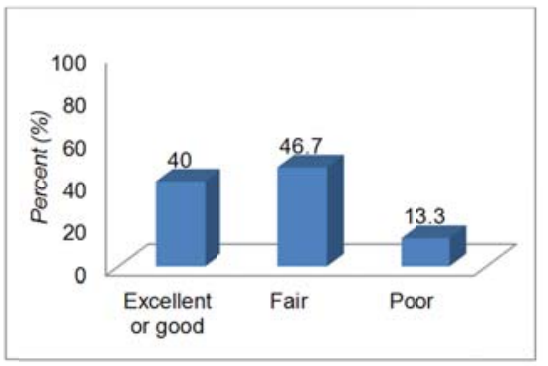

Figure 2. Respondents' ratings of students' ability to deliver behavioural support $(n=30)$

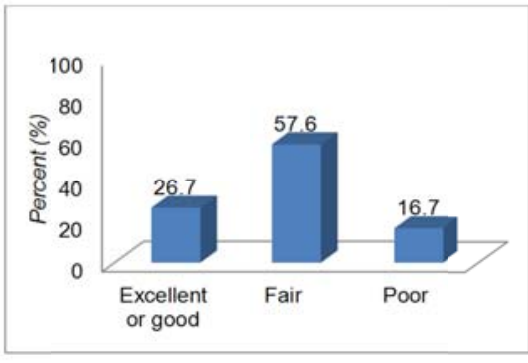

Figure 3. Respondents' ratings of students' ability to deliver advice on smoking cessation medications $(n=30)$

Forty percent of respondents reported that there are no barriers to including smoking cessation teaching on the curriculum, however a similar proportion disagreed (see Table 6). The most commonly reported barriers to teaching were lack of smoking cessation knowledge amongst staff, uncertainty about who should deliver the teaching, inconsistent government policies make it difficult to identify what should be included on the curriculum and a lack of space on the curriculum.

Table 6. Percentage of schools reporting barriers affecting efforts to teach smoking cessation

\begin{tabular}{|c|c|c|c|c|}
\hline & \multicolumn{3}{|l|}{ Percentage (n) } & \multirow{2}{*}{ Total } \\
\hline & Agree & Disagree & Neither agree nor disagree & \\
\hline There are no barriers & $40 \%(n=12)$ & $36.7 \%(n=11)$ & $23.3 \%(n=7)$ & $n=30$ \\
\hline Administrative problems & $12.5 \%(n=4)$ & $78.1 \%(n=25)$ & $9.4 \%(n=3)$ & $n=32$ \\
\hline No space on crowded curriculum & $22.6 \%(n=7)$ & $58.1 \%(n=18)$ & $19.4 \%(n=6)$ & $n=31$ \\
\hline Lack of smoking cessation knowledge amongst staff & $34.4 \%(n=11)$ & $53.1 \%(n=17)$ & $12.5 \%(n=4)$ & $n=32$ \\
\hline Lack of enthusiasm from students & $15.6 \%(n=5)$ & $59.4 \%(n=19)$ & $25 \%(n=8)$ & $n=32$ \\
\hline Inconsistent government policies & $29 \%(n=9)$ & $54.8 \%(n=17)$ & $16.1 \%(n=5)$ & $n=31$ \\
\hline Unclear who should teach smoking cessation & $34.4 \%(n=11)$ & $53.1 \%(n=17)$ & $12.5 \%(n=4)$ & $n=32$ \\
\hline Insufficient funding & $9.4 \%(n=3)$ & $56.3 \%(n=18)$ & $34.4 \%(n=11)$ & $n=32$ \\
\hline $\begin{array}{l}\text { Smoking cessation interventions not a priority for } \\
\text { students }\end{array}$ & $6.3 \%(n=2)$ & $68.8 \%(n=22)$ & $25 \%(n=8)$ & $n=32$ \\
\hline
\end{tabular}

\section{Discussion}

This is the first nationwide survey of smoking cessation teaching and training on undergraduate nursing curricula in the UK. Results showed that although almost all nursing schools reported addressing the harmful effects of tobacco use, less than two-thirds of schools reported training students in how to deliver brief interventions, such as VBA. Similar proportions reported teaching practical delivery of interventions in artificial and clinical settings and over three-quarters of schools claimed to teach ways to assist quit attempts. Findings also indicated a lack of education in nicotine addiction and its related topics. The number of teaching hours reportedly allocated to smoking cessation is low; over a third of schools spent less than three hours teaching the topic throughout the three-year nursing programme. A unique finding of our study is that nursing faculties generally reported a lack of confidence in students' ability to deliver interventions such as VBA, behavioural support and advice on smoking cessation medications. Finally, barriers such as lack of smoking cessation 
knowledge amongst staff and uncertainty about who should deliver the teaching may be affecting the teaching of smoking cessation.

Findings indicated that almost a third of nursing students are not receiving training in the delivery of brief interventions, such as VBA, despite guidelines for health professionals and MECC policy initiatives recommending that VBA be delivered to smokers at every opportunity ${ }^{[8,9]}$. Furthermore, only just over half of respondents demonstrated confidence in students' ability to deliver VBA upon completion of the programme. This novel finding indicates that despite many programmes providing training, schools may be aware that nursing programmes are not adequately preparing nurses to deliver brief interventions in practice. Brief advice to stop smoking has been shown to be the most cost-effective intervention currently available ${ }^{[11]}$ and evidence-based training in VBA is freely accessible via the NCSCT website, which takes no longer than 30 minutes to complete. If all undergraduate nurses were trained in VBA using the NCSCT training programme, more quit attempts would be generated, resulting in more referrals to the stop smoking services, more successful quit attempts and therefore more long-term ex-smokers ${ }^{[16]}$. Routine integration of training in VBA in nursing curricula is necessary if the Tobacco Control Plan to reduce adult smoking prevalence in England to $18.5 \%$ or less is to be met by $2015^{[3]}$. Nurses may further benefit from training in VBA as these skills are transferable to a range of issues such as providing advice on alcohol consumption ${ }^{[34]}$. Nevertheless, the current findings show that UK nursing programmes report typically providing more training in brief interventions than UK medical schools and nursing programmes in the USA and Asia $^{[24,27,28]}$.

Over three-quarters of schools reported teaching ways to assist quit attempts, such as behavioural support and/or advice on smoking cessation medications. Despite this initially encouraging result, there was a distinct lack of confidence in students' ability to deliver behavioural support and advice on smoking cessation medications, which further questions the quality of teaching and practical training on UK nursing curricula. Under two-thirds of schools also reported providing teaching in practical delivery in artificial or clinical settings. Previous studies have found that many nurses perceive a lack of confidence in their ability to deliver smoking cessation interventions due to lack of training, which negatively impacts their smoking cessation practices ${ }^{[18,19]}$. Opportunity to practice acquired knowledge and skills is desirable to promote students' consolidation of learning, in order to deliver effective interventions in practice ${ }^{[28]}$. These results suggest that it may be beneficial to prioritise training in VBA over teaching of ways to assist quit attempts and practical delivery, in order to fully prepare nurses to meet the recommended guidelines for health professionals and MECC initiatives ${ }^{[8,9]}$. Quit attempts generated from VBA may be assisted by local stop smoking services, whilst teaching of ways to assist quit attempts and teaching in practical delivery may be better placed on post-graduate programmes where students may specialise as smoking cessation practitioners, if their clinical setting allows it.

The finding that only just over a quarter of respondents were confident in students' ability to deliver advice on smoking cessation medications is unsurprising given that around half of schools reported a lack of education in nicotine addiction and its related topics, such as withdrawal symptoms and smoking cessation medications. These results are of particular concern as knowledge of the nature of nicotine addiction and withdrawal symptoms are necessary for health professionals to understand the process of quitting and relapsing ${ }^{[9]}$. Furthermore, it questions the methods to assist quit attempts that are being taught if schools omit education related to nicotine addiction. Similarly, only half of schools reported teaching the cost- and clinical-effectiveness of smoking cessation interventions. A previous study of UK practice nurses found that many nurses lack knowledge of the clinical- and cost-effectiveness of NRT and that those who had not been trained in this area were less likely to recommend NRT and know that NRT is cost-effective ${ }^{[22]}$. A lack of education in this area may lead to incorrect beliefs about interventions and subsequent inadequate smoking cessation practices by future nurses. This gap in education has also been found in UK medical schools and nursing programmes in the USA and Asia ${ }^{[24,27,28]}$.

Virtually all schools reported that they do not examine students' knowledge and skills in smoking cessation, a finding that is consistent with UK medical schools and nursing programmes in the USA ${ }^{[24,28]}$.Without examinations, it is not possible to evaluate the quality and effectiveness of teaching and training or whether students are truly acquiring the adequate 
knowledge and skills to deliver successful interventions ${ }^{[35]}$. Assessment of education and delivery of interventions is imperative in order to establish effective smoking cessation education on UK nursing curricula. Examinations, particularly in the delivery of VBA, must be integrated in undergraduate nursing curricula to ensure that the next generation of nurses delivers VBA effectively. This lack of examinations in UK nursing schools also highlights misplaced confidence of universities in students' abilities to deliver smoking cessation interventions. Furthermore, lack of examinations might indicate the low priority given to smoking cessation on nursing curricula. The reporting of lack of space on the curriculum as a barrier to teaching and the lack of teaching hours reportedly allocated to teaching further supports this conclusion ${ }^{[9]}$.

The majority of schools indicated that a member of staff delivered the teaching, however as lack of smoking cessation knowledge amongst staff and uncertainty about who should deliver the teaching were reported as barriers to teaching; it is questionable whether faculties are adequately qualified to deliver smoking cessation education. Uncertainty about who should deliver the teaching was also reported as a barrier to teaching in UK medical schools, which suggests that nursing and medical faculties in the UK are under-prepared to deliver smoking cessation education ${ }^{[24]}$. Nursing schools may refer to the national training standard for smoking cessation on the NCSCT website, which provides evidence-based recommendations for smoking cessation training. These resources are also able to provide staff the knowledge required to deliver effective smoking cessation education.

The present study has several limitations to consider. It is not able to comment on the quality of teaching and training as data was not collected on intensity of education (e.g. brief vs. detailed), whether topics were part of required or optional courses, nor the resources on which teaching is based. Similarly, items regarding training in brief interventions and teaching of ways to assist quit attempts are not specific about what methods are being taught. This prevents the present study from identifying in detail which interventions are included on nursing curricula. Self-administered surveys are susceptible to the effect of social desirability, which may have caused respondents to over-report smoking cessation education, and to the inability of faculty to accurately remember the smoking cessation content on the curriculum. It is also possible that the response rate of the present study may have introduced selection bias to the results. Schools that did not respond may have included less smoking cessation education on the curriculum, which would result in an overestimation of smoking cessation education in the current study. However, this is unlikely given that similar results of smoking cessation education were found in a study of UK medical schools that had a response rate of $96 \%{ }^{[24]}$. Additionally, the current survey was not validated nor tested for reliability, however it was piloted prior to distribution and a study of UK medical schools used a similar survey to the present study ${ }^{[24]}$. Finally, it is possible that topics included on curricula and the inclusion of examinations change each year depending on the curricula set by educators.

The current study did not investigate the impact of faculty-related factors upon smoking cessation education. A previous study found that smoking status of nursing programme directors affected the amount of teaching time dedicated to smoking cessation topics on curricula ${ }^{[36]}$. Further research on this topic is therefore warranted. Future research may also consider identifying whether newly qualified nurses' recollections of smoking cessation education and training matches that of faculties, as a previous study of UK medical schools found a poor correlation between students that had graduated and deans of the nursing programmes ${ }^{[24]}$.

Notwithstanding it's limitations, the present study concludes that whilst UK nursing curricula appears to generally report the inclusion of teaching the harmful effects of tobacco use on curricula, this is unlikely to translate to clinical intervention given the short amount of time dedicated to smoking cessation in the curriculum, the absence of assessment and the low confidence in students' abilities to deliver interventions. UK nursing curricula do not appear to be adequately preparing undergraduate nurses to meet the current smoking cessation guidelines for health professionals. Consequently, UK nursing schools are not fulfilling their potential in contributing to the reduction in smoking prevalence ${ }^{[8,9]}$.

\section{Acknowledgements}

Thanks to Daniel West and Mathew West of Silverback for their help with the online survey. Thanks also to the staff of the NCSCT for their help in testing the online survey. 


\section{References}

[1] Dunstan, S., \& Robinson, S. General Lifestyle Survey overview: A report on the 2010 General Lifestyle Survey. London: Office for National Statistics, 2012. Available from: http://www.ons.gov.uk/ons/rel/ghs/general-lifestylesurvey/2010/index.html.

[2] Office for National Statistics (ONS) General Lifestyle Report Overview: A report on the 2010 General Lifestyle Survey. London, Office for National Statistics, 2012.

[3] Department of Health. Healthy Lives, Healthy People: A Tobacco Control Plan for England, 2011. Available from: https://www.gov.uk/government/uploads/system/uploads/attachment_data/file/213757/dh_124960.pdf.

[4] The Scottish Government. Tobacco Control Strategy - Creating a Tobacco-Free Generation, 2013. Available from: http://www.scotland.gov.uk/Publications/2013/03/3766.

[5] Welsh Government. Tobacco Control Action Plan for Wales, 2012. Available from: http://wales.gov.uk/topics/health/improvement/index/tobaccoplan/?lang=en.

[6] Doll, R., Peto, R., Boreham, J., \& Sutherland, I. Mortality from cancer in relation to smoking: 50 years observations on British doctors. British Journal of Cancer. 2005; 92(3): 426-429. PMid:15668706

[7] Raw, M., McNeill, A., \& West, R. Smoking cessation guidelines for health professionals - a guide to effective smoking cessation interventions for the healthcare system. Thorax. 1998; 53: S1-S18. http://dx.doi.org/10.1136/thx.53.2008.S1

[8] Department of Health. The NHS's Role in the Public's Health, 2012. Available from: https://www.gov.uk/government/uploads/system/uploads/attachment_data/file/216423/dh_132114.pdf.

[9] West, R., McNeill, A., \& Raw, M. Smoking cessation guidelines for health professionals: an update. Thorax. 2000; 55(12): 987-999. PMid:11083883 http://dx.doi.org/10.1136/thorax.55.12.987

[10] West, R. Stop smoking services: increased chances of quitting. NCSCT Briefing No.8. London: National Centre for Smoking Cessation and Training, 2012.

[11] Anczak, J. D., \& Nogler, R. A. Tobacco cessation in primary care: maximizing intervention strategies. Clinical Medicine \& Research. 2003; 1(3): 201-216. http://dx.doi.org/10.3121/cmr.1.3.201

[12] Aveyard, P., Begh R., Parsons, A., \& West, R. Brief opportunistic smoking cessation interventions: a systematic review and meta-analysis to compare advice to quit and office assistant. Addiction. 2012; 107(6): 1066-1073. PMid:22175545 http://dx.doi.org/10.1111/j.1360-0443.2011.03770.x

[13] Law, M., \& Tang, J. An analysis of the effectiveness of interventions intended to help people stop smoking. Archives of Internal Medicine. 1995; 155(18): 1933-1941. PMid:7575046 http://dx.doi.org/10.1001/archinte.1995.00430180025004

[14] American Nurses Association (ANA). Nursing: Scope and Standards of Practice. Washington DC, 2004.

[15] Rice, V. H., \& Stead, L. F. Nursing interventions for smoking cessation. Cochrane Database of Systematic Reviews. 2008. http://dx.doi.org/10.1002/14651858.CD001188.pub3

[16] Hughes, L., McIlvar, M., \& McEwen, A. How to advise and refer inpatients who smoke. Nursing Times. 2012; 109(1-2): 14-16.

[17] Carson, K. V., Verbiest, M .E. A., Crone. M. R., Brinn, M. P. Esterman, A. J., Assendelft, W. J. J., et al. Training health professionals in smoking cessation. Cochrane Database of Systematic Reviews. 2012; 5. Art no: CD000214. http://dx.doi.org/10.1002/14651858.CD000214.pub2

[18] Hall, S., Vogt, F., \& Marteau, T. M. A short report: survey of practice nurses’ attitudes towards giving smoking cessation advice. Family Practice. 2005; 22(6): 614-616. PMid:16055470 http://dx.doi.org/10.1093/fampra/cmi082

[19] Chan, S. S., Sarna, L., Wong, D. C., \& Lam, T. H. Nurses’ tobacco-related knowledge, attitudes, and practices in four major cities in China. Journal of Nursing Scholarship. 2007; 39(1): 46-53. PMid:17393965 http://dx.doi.org/10.1111/j.1547-5069.2007.00142.x

[20] Good., M. J., Frazier, L. M, Wetta-Hall, R., Ablah, E., \& Molgaard, C. A. Kansas office-based nurses’ evaluation of patient tobacco cessation activities. Journal of Community Health Nursing. 2004; 21(2): 77-85. PMid:15123437 http://dx.doi.org/10.1207/s15327655jchn2102_02

[21] Sarna, L. P., Brown, J. K., Lillington, L., Rose, M., Wewers, M. E., \& Brecht, M. L. Tobacco interventions by oncology nurses in clinical practice. Cancer. 2000; 89(4): 881-889. http://dx.doi.org/10.1002/1097-0142(20000815)89:4<881::AID-CNCR22>3.0.CO;2-M

[22] McEwen, A., \& West, R. Smoking cessation activities by general practitioners and practice nurses. Tobacco Control. 2001; 10(1): 27-32. PMid:11226357 http://dx.doi.org/10.1136/tc.10.1.27

[23] World Health Organisation (WHO). (2005). WHO informal meeting on health professionals and tobacco control. Code of practice on tobacco control for health professionals. Available from: http://www.who.int/tobacco/communications/events/codesofpractice/en/index.html.

[24] Roddy, E., Rubin, P., \& Britton, J. A study of smoking and smoking cessation on the curricula of UK medical schools. Tobacco Control. 2004; 13(1): 74-77. PMid:14985601 http://dx.doi.org/10.1136/tc.2003.004572 
[25] Nursing and Midwifery Council. (2004). Standards of Proficiency for Pre-Registration Nursing Education. Available from: www.nmc-uk.org/Documents/Standards/nmcStandardsofProficiencyForPre_RegistrationNursingEducation.pdf

[26] Chan, S. S., Sarna, L., \& Danao, L.L. Are nurses prepared to curb the tobacco epidemic in China? A questionnaire survey of schools of nursing. International Journal of Nursing Studies. 2008; 45(5): 206-713. PMid:17336307 http://dx.doi.org/10.1016/j.ijnurstu.2006.12.008

[27] Sarna, L., Danao, L. L., Chan, S. S. C., Shin, S. R., Baldago, L. A., Endo, E., Wewers, M. E. Tobacco control currcula content in baccalaureate nursing programs in four Asian nations. Nursing Outlook. 2006; 54(6): 334-344. PMid:17142152 http://dx.doi.org/10.1016/j.outlook.2006.09.005

[28] Wewers, M. E., Kidd, K., Armbruster, D., \& Sarna, L. Tobacco dependence curricula in U.S. baccalaureate and graduate nursing education. Nursing Outlook. 2004; 52(2): 95-101. PMid:15073590 http://dx.doi.org/10.1016/j.outlook.2003.09.007

[29] Heath, J., Andrews, J., Thomas, S. A., Kelley, F. J., \& Friedman, E. Tobacco dependence curricula in acute care nurse practitioner education. American Journal of Critical Care. 2002; 11(1): 27-33. PMid:11785554

[30] Hornberger, C. A., \& Edwards, L. C. Survey of tobacco cessation curricula in Kansas nursing programs. Nurse Educator. 2004; 29(5): 212-216. PMid:15371764 http://dx.doi.org/10.1097/00006223-200409000-00014

[31] Riva, G., Teruzzi, T., \& Anolli, L. The use of the internet in psychological research: comparison of online and offline questionnaires. Cyber Psychology \& Behavior. 2003; 6(1): 73-80. PMid:12650565 http://dx.doi.org/10.1089/109493103321167983

[32] Dillman, D. A. Mail and Internet Surveys: The Tailored Design Method. New York: Willey-Interscience, 2000.

[33] Edwards, P., Roberts, I., Clarke, M., DiGuiseppi, C., Pratap, S., Wentz, R., Cooper, R. Methods to increase response rates to postal questionnaires. Cochrane Database of Systematic Reviews. 2007; 2 (10.1002).

[34] McQueen, J., Howe, T. E., Allan, L., Mains, D., \& Hardy, V. Brief interventions for heavy alcohol users admitted to general hospital wards. Cochrane Database Syst Rev. 2011. PMid:21833953 http://dx.doi.org/10.1002/14651858.CD005191.pub3

[35] Rust, C. The impact of assessment on Student learning: how can the research literature practically help to inform the development of departmental assessment strategies and learner-centred assessment practices? Active Learning in Higher Education. 2002; 3(2): 145-158. http://dx.doi.org/10.1177/1469787402003002004

[36] Price, J. H., Joran, T. R. Jeffrey, J. D., Stanley, M. S., \& Price, J. A. Tobacco intervention training in graduate psychiatric nursing education programs. Journal of the American Psychiatric Nurses Association. 2008; 14(2): 117-124. PMid:21665760

http://dx.doi.org/10.1177/1078390307311973 